\title{
UM ROTEIRO TEÓRICO-LITERÁRIO \\ PARA PENSAR O PAPEL DA NARRAÇÃO ORAL HOJE
}

Gilka Girardello ${ }^{1}$

\section{RESUMO}

Este trabalho reflete sobre um conjunto de referências teóricas e literárias que consideramos úteis para uma abordagem à narração oral enquanto possibilidade poética e forma artística no cenário cultural contemporâneo. Para a escolha dessas referências, todas clássicas em diferentes campos de estudos narrativos, pautamonos pela sua possível pertinência em relação aos debates em circulação em alguns dos contextos empíricos onde se estuda e conta histórias, hoje, no Brasil. Indicamos, assim, a importância dos conceitos de arte verbal e performance (Richard Bauman e Paul Zumthor), da relação entre narrativa e memória cultural (Lyotard) e da abertura à emergência de novas narratividades, sugerida por Ricoeur, Kearney, DidiHuberman e Gagnebin a partir de suas leituras do clássico ensaio "O Narrador", de Walter Benjamin. Buscando contribuir para valorizar práticas como o contar histórias, cuja presença nas escolas e em outros espaços culturais brasileiros é crescente, e apoiar a constituição de parâmetros de pesquisa ético-estética cada vez mais elevados nesse campo, conclui-se afirmando a singularidade do papel da narração oral nas mediações exigidas pela complexa teia cultural contemporânea.

Palavras-chave: Narrativa. Histórias. Oralidade. Performance. Arte Verbal. 


\title{
THEORETICAL-LITERARY CONSIDERATIONS ABOUT THE ROLE OF ORAL NARRATION TODAY
}

\begin{abstract}
This article reflects on a group of theoretical and literary references that we consider useful to an approach to oral narration as a poetic possibility and artistic form in the contemporary cultural scene. To choose these references, all of which are classics in various fields of narrative studies, we considered their possible relevance to debates in empirical contexts where stories are studied and told in Brazil today. We indicate the importance of the concepts of verbal art and performance (Richard Bauman and Paul Zumthor), the relation between narrative and cultural memory (Lyotard) and the opening to the emergence of new narratives suggested by Ricoeur, Kearney, DidiHuberman and Gagnebin in their discussions based on Walter Benjamin's classic essay "The Storyteller." The paper concludes by affirming the singularity of the role of oral narration in the mediations required by the complex contemporary cultural web. It seeks to contribute to the valorization of practices such as storytelling, which has a growing presence in Brazilian schools and other cultural spaces, and support the establishment of increasingly higher ethical-aesthetic standards for research in this field.
\end{abstract}

Keywords: Narrative. Storytelling. Performance. Verbal art. 
A reflexão pedagógica mais fecunda encontra-se às vezes fora da pedagogia, ali onde se cruzam, por exemplo, os sonhos ativos dos poetas e as histórias nascidas nas profundidades da vida popular, para uma apreensão mais viva da realidade múltipla do mundo por parte das crianças e dos homens.

Georges Jean (1990, p. 10).

Este trabalho pretende alinhar-se à reivindicação de uma pedagogia poética feita pelo poeta e ensaísta Georges Jean, autor da epígrafe acima, para quem a tarefa prioritária dos educadores, anterior mesmo a qualquer invenção pedagógica, seria "a invenção de si mesmos" (JEAN, 1990, p. 12). É uma tarefa cuja delicadeza e desafio bem conhecemos, até porque nos situamos dentro do universo da educação, como supomos que se situem também aqueles(as) que nos leem agora. E, após várias décadas vivendo esse contexto, podemos sem dúvida concordar com Jean em que a arte, a imaginação e a poesia são nossos maiores aliados no processo de invenção de nós mesmos. Este artigo, assim, procura sugerir ou relembrar nexos entre alguns dos desafios que as asperezas do cenário contemporâneo colocam a todos nós, professores, e esse recurso tão singelo e primordial do encontro humano: o poder poético da palavra falada.

Sem a pretensão de abarcar sistematicamente qualquer totalidade, nosso objetivo aqui é compartilhar leituras e intuições, motivadas por uma escuta de muitos anos ao que se diz em contextos como o da formação de professores para a infância, o das redes de contadores de história contemporâneos e o dos estudos da narrativa e da performance - nas Artes, na Antropologia, nos Estudos da Linguagem e na Filosofia. Algumas das questões que reverberam nesses espaços nos sensibilizam mais diretamente: a persistência do papel da narrativa na múltipla e 
intensa rede em que se constituem as configurações contemporâneas da cultura; a riqueza da oralidade popular e a necessidade de que ela seja mais valorizada e conhecida pelos educadores; a importância de um diálogo maior entre os educadores e artistas da oralidade e as ideias de alguns pensadores contemporâneos, hoje já considerados clássicos em seus campos de estudo, sobre arte verbal, performance, narrativa, memória cultural e fazer poético. Este trabalho, enfim, procura ser um dizer nesse diálogo; ou, considerando que falaremos de performance (e de metáforas), procura ser um gesto no sentido desse diálogo.

Propomos começar por um texto pouco conhecido de Paulo Freire que anuncia os temas que estarão em foco, particularmente o papel da invenção poética na oralidade. O texto faz parte de uma entrevista publicada em 1984 em folheto do Núcleo de Memória Popular do ABC, e consiste na rememoração de uma cena da infância do autor em Pernambuco:

Eu me lembro que nos silêncios de tarde, de uma hora da tarde, duas horas, de poeira de calor. Eu me lembro que esse silêncio era cortado pelo grito suave, anunciando o que ele chamava de "Menô de Engenho", que não era outra coisa senão mel novo de engenho. E ele dizia Menô de Engenho. Ele devia ter seus 70 anos no tempo que eu tinha 10,11 anos. Me lembro também do homem que gritava "Ostra! É ostra, ostra, ostra chegada agora!". Os homens que vendiam bananas, as mulheres, o homem que carregava no ombro toda uma casa de comércio, e dizem que vendia espanador, vasculhador, esteira d'angola, vassoureiro, grelha...ritmado! Me lembro de um cara que passava correndo, e isso até pus num poema que escrevi e nunca publiquei. Passava correndo com o tabuleiro na cabeça e gritando: "Doce de banana e goiaba! Doce de banana e goiaba!". E eu e meus companheiros nos escondíamos nas esquinas por onde ele passava e gritávamos: "Quero doce de banana!". E ele, sem parar, sem olhar pra trás, sempre apressado, continuava dizendo...dizia: "Não tenho banana. Grito banana porque é meu hábito. Doce de banana e goiaba! Doce de banana e goiaba!" No fundo, aquele homem era muito mais um artista que um 
vendedor, o que ele não queria era perder o ritmo." (FREIRE, 1984, p.16. Grifos meus).

Esse relato é um testemunho do potencial artístico da palavra oral e da presença humana criadora nos mais diversos contextos sociais e culturais. Ele assinala também o quanto há de valioso e inspirador na oralidade tradicional da cultura brasileira, ainda insuficientemente conhecida por muitos dos narradores contemporâneos - professores, atores, bibliotecários, animadores de leitura - que atuam em contextos escolares ou escolarizados.

É interessante o paralelo entre a recordação de Paulo Freire, citada acima, e o relato do medievalista e estudioso da oralidade suíço Paul Zumthor sobre o encantamento que sentia, quando era criança na Paris nos anos 1930, diante dos poetas populares e cantores de rua:

Havia o homem, o camelô, sua parlapatice, porque ele vendia as canções, apregoava e passava o chapeu; as folhas volantes em bagunça num guarda-chuva emborcado na beira da calçada. Havia o grupo, o riso das meninas, sobretudo no fim de tarde, na hora em que as vendedoras saíam de suas lojas, a rua em volta, os barulhos do mundo, e, por cima, o céu de Paris que, no começo do inverno, sob as nuvens de neve, se tornava violeta. Mais ou menos tudo isso fazia parte da canção. Era a canção. (ZUMTHOR, 2000, p. 33).

Ele conta que um dia resolveu comprar um dos folhetos, tentando guardar para si o encantamento que sentia, porém frustrou-se, já que "lê-lo não ressuscitava nada" (idem), e mesmo cantar a melodia de memória era insuficiente para reeditar a força da presença daquela forma artística, que, segundo ele, só existe na vida da performance. Para Zumthor, a competência da performance oral não é da ordem de um saber-fazer, como poderia parecer à primeira vista, mas sim de um saber-ser 
(p.35), de uma presença em que o corpo está inteiramente implicado, e cujo estatuto poético é definido pelo critério do prazer:

\begin{abstract}
Que um texto seja reconhecido por poético (literário) ou não, depende do sentimento que nosso corpo tem. Necessidade para produzir seus efeitos; isto é, para nos dar prazer. É este, a meu ver, um critério absoluto. Quando não há prazer - ou ele cessa - o texto muda de natureza. (ZUMTHOR, 2000, p. 41).
\end{abstract}

A noção de arte verbal como performance transcende o foco no texto escrito, estendendo-se à narrativa oral e às canções populares em diferentes culturas. Ela vem sendo discutida em profundidade, desde a década de 1970, pelo antropólogo norte-americano Richard Bauman, a partir da antropologia linguística. Entre suas pesquisas está um estudo etnográfico dos pregões de vendedores no mercado de Guanajato, no México, identificando neles "um grau de elaboração que coloca a função poética em destaque, através de uma gama de mecanismos que atraem a atenção do ouvinte para as propriedades formais do ato de expressão (BAUMAN, 2008, p.9). ${ }^{2}$ Esses mecanismos são, por exemplo, as repetições, aliterações e a padronização prosódica da entonação. Para ele, "toda poética é poética em ação, toda poética é performativa" (BAUMAN, 2008, p. 5) e entre os objetivos intrínsecos da arte verbal na performance está o enriquecimento da experiência" (BAUMAN, 1974, p. 302). O autor observa que existe um contínuo entre dois polos na arte verbal: em um extremo está o papel da memorização fiel de um texto previamente existente, oral ou escrito; no outro, a geração de um texto completamente novo durante a situação de performance. O mais importante, afirma ele, é perceber que "entre esses dois pólos está toda uma variedade de estruturas textuais emergentes, encontradas nas performances empíricas" (BAUMAN, 1974, p. 303). Bauman 
defende, assim, que "a performance possa estabelecer um nexo entre tradição, prática e as emergências na arte verbal" (p. 306). Essa ideia nos parece das mais preciosas para uma afirmação da singularidade do papel da performance narrativa na complexa teia cultural contemporânea, onde convivem - muitas vezes ao toque de um clique ou lado a lado na mesma tela - manifestações e heranças com raízes em tempos e espaços muito diversos.

Para retornar adiante e com maior propriedade a este tema, e em um esforço de síntese conceitual apoiado, também, em iluminações provenientes da literatura, situaremos a seguir um horizonte de relações entre narrativa, cultura e a persistência do papel da narrativa, especialmente na performance oral, como espaço de exercício poético.

\section{O FAZER POÉTICO DAS HISTÓRIAS}

A grande missão da poesia, já dizia Aristóteles, era fabricar o que poderia ter acontecido, ou, em outras palavras, imaginar histórias ${ }^{3}$. A ênfase no fazer narrativo é central, também, na obra magistral de Paul Ricoeur (1994), que o vê como um movimento, um salto, uma ação, que é inclusive lúdica. O percurso narrativo, para ele, atualiza o que se passa na "clareira luminosa" da imaginação, onde "brincamos" com diferentes possibilidades. Ricoeur vê no próprio tecer da intriga (o mito, a fábula) "uma autêntica inteligência narrativa que precede, de fato e de direito, qualquer reconstrução do narrar" (1994, p.33). Para desenvolver a noção de inteligência narrativa, Ricoeur lembra que a definição do todo constituído pela intriga (ou mito), na Poética de Aristóteles - aquilo que tem um começo, um meio e um fim é muito mais lógica do que cronológica, estando a ênfase na ausência do acaso e 
nas necessidades que organizam a sucessão. Procurando entender que lógica é essa, Ricoeur aponta que ela é uma inteligibilidade do campo da práxis, próxima à inteligência da ação: "A poesia é, com efeito, um fazer, e um fazer sobre um fazer." (RICOEUR, 1994, p. 68) Só que não se trata de um fazer efetivo, diz ele, mas inventado. A inteligência narrativa, definida por Ricoeur, é portanto uma atividade, uma produção, já que a imitação (mimese) não decalca nem presentifica um real preexistente, sendo antes uma imitação criadora (RICOEUR, 1994, p. 76).

O fazer narrativo é indissociável do acervo imaginário da cultura, do "repertório do potencial, do hipotético, de tudo quanto não é, nem foi e talvez não seja, mas que poderia ter sido" (CALVINO,1990, p.106). Esse acervo é frequentemente descrito como um reservatório de histórias em estado "líquido", como um "mar de histórias", uma metáfora na qual entram em jogo noções como profundidade, transformação e intermediação entre diferentes universos de significação: entre água e ar, entre imagem e palavra, entre imaginação e narrativa. Um dos autores de ficção que utiliza a imagem de um mar de histórias como metáfora para a textura narrativa da cultura é Salman Rushdie, na fantasia política Haroun e o Mar de Histórias (RUSHDIE, 1991). Essa textura é, na concepção de Rushdie, fluida, complexa, cambiante e, sobretudo, viva. Pode ser aproximada da imaginação narrativa descrita por Italo Calvino: um repertório do potencial humano. Esse potencial é dinâmico; em um trecho do livro, o menino-protagonista fica receoso de que a turbulência causada na água do mar-dos-fios-de-histórias pelo pássaro-gigante que o carrega velozmente nas costas possa atrapalhar as histórias, mas um de seus companheiros responde que não há problema: "Qualquer história digna de ser contada aguenta bem uns sacolejos!" (idem, p. 69). Podemos acrescentar que, como sugere o ditado 
"quem conta um conto aumenta um ponto", contar uma história significa necessariamente lhe dar uns sacolejos; aí está a vida da narrativa.

Mais que um acervo, o mar de histórias do romance de Rushdie é um organismo. Um de seus mecanismos reguladores são os peixes-milbocas, cuja função é assim relatada por um personagem:

Quando estão com fome eles engolem histórias por todas as bocas e lá nas suas entranhas acontece um milagre: um pedacinho de uma história se junta com uma idéia de outra, e pronto! Quando eles cospem as histórias, elas já não são mais as mesmas, antigas; são outras, novas. [...] Nenhuma história vem do nada; as histórias novas nascem das velhas. São as novas combinações que fazem com que elas sejam novas. (RUSHDIE, 1991, p. 74).

Os peixes-milbocas que habitam o mar de histórias e recombinam seus fios, revitalizando-o, são descritos como "os artistas da fome." A arte narrativa aparece, assim, como um mecanismo inerente ao tecido da cultura: há milhares de peixesmilbocas no mar, e assim a tarefa recriadora pertence ao conjunto da viva tapeçaria da cultura. Esta é outra imagem que nos parece muito lúcida para compreender o papel da narração oral no mundo de hoje, por valorizar o papel de uma criação autoral marcada ao mesmo tempo pela independência e agilidade do impulso individual e pela inserção rizomática no imaginário coletivo.

\section{A PERSISTÊNCIA DA NARRATIVA}

O romance de Rushdie, ainda que atravessado por humor e ironia, denota apreensão com o futuro do Mar das Histórias. A principal ameaça sobre ele é o Príncipe do Silêncio - e não podemos deixar de lembrar que o autor escreveu o livro 
em esconderijos, após sua condenação à morte pelo fundamentalismo islâmico. Mas existe uma outra ameaça, mencionada apenas de passagem, quando um personagem lamenta o estado da água - envenenada, fria, viscosa - na chamada Zona Velha do oceano:

- A culpa é nossa! Nós somos os Guardiões do Oceano, e deixamos de guardá-lo. Vejam só esse Mar! As histórias mais antigas que já foram inventadas -- vejam em que estado elas estão! E fomos nós que as deixamos apodrecer, nós que as abandonamos, muito antes de começar esse envenenamento. Perdemos o contato com as nossas origens, nossas raízes, nossa Nascente, nossa Fonte! São histórias chatas, não interessam mais, é o que dizíamos; não há mais demanda, há excesso de oferta. E agora, olhem, olhem só! Sem cor, sem vida, sem nada. Estragadas! Arruinadas! (RUSHDIE, 1991, p.126).

A advertência é contra o esquecimento que asfixia a tradição, e contra o perigo de que algo muito precioso esteja virando ruína nesse processo. Isto acontece, sugere o autor, em função das leis de mercado, em que há excesso de oferta para pouca demanda. Essa oferta torrencial de histórias - pelos meios de comunicação, supõe-se - nos faz pensar no "dilúvio de imagens pré-fabricadas" de que fala Calvino (1990, p. 107), também receoso de que elas asfixiem o trabalho de recriação imaginária da cultura. Haroun e o Mar de Histórias é uma obra de fantasia exuberante, mas é também um manifesto político que detecta uma tendência de perda cultural, e que talvez só não tenha um tom melancólico em razão do mesmo engajamento que levou o autor a endereçá-lo também às crianças.

Nesse sentido, o livro pertence à tradição de "narrativas sobre o fim da narrativa", em que Jeanne Marie Gagnebin (1994) insere o ensaio O Narrador de Walter Benjamin, referência obrigatória em qualquer roteiro de estudo sobre a 
narrativa na cultura. No ensaio, como é bem sabido, Benjamin diz que "a arte de narrar está em vias de extinção" (BENJAMIN, 1994, p. 197), e que são cada vez mais raras as pessoas que sabem contar histórias. Para ele, é como se estivesse sendo perdida a faculdade de trocar experiências. Gagnebin observa que, embora o tom melancólico esteja bem presente no ensaio $O$ Narrador, ele não é exclusivo, e há também espaço para um tom diferente, "construtivista" (GAGNEBIN, 1994a, p. 10), apontando para possíveis novas formas de narratividade que acompanhariam uma reconstrução da experiência: "A uma experiência e uma narratividade espontâneas, oriundas de uma organização social comunitária centrada no artesanato, opor-se-iam, assim, formas 'sintéticas' de experiência e de narratividade" (GAGNEBIN, 1994a, p. 9-10). Colocando o leitor na posição de quem está livre para dar ele mesmo explicações ao que lê, a narração aponta para além dela própria, "para a atividade da leitura e da interpretação" (GAGNEBIN, 1994a, p.13). Ela vê aí a sugestão de "uma atividade narradora que salvaria o passado, mas saberia resistir à tentação de preencher suas faltas e de sufocar seus silêncios" (GAGNEBIN, 1994b, p. 72-73), o que percebe como uma antecipação do conceito de obra aberta que viria a ser formulado mais tarde por Umberto Eco.

Três outras leituras recentes do ensaio de Benjamin fazem considerações no mesmo sentido, mais construtivo, que nos ajuda a situar o papel da narrativa na contemporaneidade. Paul Ricoeur, após comentar o ensaio em seu clássico Tempo e Narrativa (1984), manifesta uma espécie de fé na permanência da função narrativa:

Talvez seja necessário, apesar de tudo [...], acreditar que novas formas narrativas, que ainda não sabemos denominar, estejam nascendo; elas atestarão que a função narrativa pode se metamorfosear, mas não morrer. Pois não temos qualquer ideia do que seria uma cultura em que não se 
soubesse mais o que significa narrar. (RICOEUR, 1995, p. 46).

Outra leitura na mesma direção é a do filósofo irlandês Richard Kearney, para quem Benjamin não estava se referindo ao fim da narração de histórias propriamente dita: "Ele apenas assinalava a derrocada iminente de certas formas de recordação que pressupunham tradições ancestrais de experiência herdada, transmitidas fluentemente de uma geração para a seguinte. Isso de fato acabou." (KEARNEY, 2012, p. 410) Observando, porém, o surgimento de novas formas de narrar adequadas aos novos cenários sociais e culturais, o autor elabora uma visão afirmativa da narratividade, na qual a mimesis é entendida "como uma forma criativa de recontar, evitando assim as conotações de representação servil erradamente associadas ao tradicional termo "imitação". (KEARNEY, 2012, p. 415). A partir de Ricoeur, o autor destaca o caráter ativo do processo de criação narrativa, um movimento que parte da feição potencialmente narrativa da experiência vivida e volta a ela reconfigurado, convidando à responsividade ética e poética:

o ato de mimesis envolve um movimento circular da ação ao texto e de volta à ação - passando da experiência pre-figurada para o recontar narrativo e de volta a um mundo da vida refigurado. Em suma, a vida está sempre a caminho da narrativa, mas não chega lá até que alguém escute e conte essa vida como uma história. (KEARNEY, 2012, p. 415).

Outro leitor de Benjamin que discorda das interpretações fatalistas do ensaio $O$ Narrador é Georges Didi-Huberman, a partir de uma atenção às nuances do texto benjaminiano no original alemão. Ele diz que todo o vocabulário utilizado por Walter Benjamin no ensaio "é, sem dúvida, o do declínio" (DIDI-HUBERMAN, 2011, p. 122) o declínio da experiência ligada à narrativa. Mas, acrescenta, é um declínio "que 
supõe a persistência das coisas decaídas" (idem), não um dado mas um processo, e aberto a ressurgências.

\begin{abstract}
Quando Benjamin nos diz que "a arte da narrativa tende a se perder", ele expressa ao mesmo tempo um horizonte de "fim" (Ende) e um movimento sem fim (neigen: pender/debruçar-se, inclinar, abaixar) [...]. Trata-se portanto, da questão do "declínio" e não de desaparição efetuada: a palavra Niedergang, empregada [...] por Benjamin, significa a descida progressiva, o pôr do sol, o ocidente (isto é, um estado de sol que desaparece de nossas vistas, mas nem por isso deixa de existir em outro lugar, sob nossos passos, nos antípodas, com a possibilidade, o "recurso", de que ele reapareça do outro lado, no oriente." (DIDI-HUBERMAN, 2011, p. 122-123).
\end{abstract}

A proposta de Didi-Huberman, inspirada no conceito de "imagem dialética" de Benjamin, é apostar nas possíveis ressurgências e sobrevivências da experiência, do pensamento e da imaginação: "Somos 'pobres em experiência'? Façamos dessa mesma pobreza - dessa semiescuridão - uma experiência" (idem, p.127). Ele cita vários exemplos dessas sobrevivências da experiência humana nos contextos mais adversos, como os diários escritos no gueto de Varsóvia e no campos de extermínio nazistas, lançados ao futuro como mensagens em garrafas lançadas ao mar, "cujo lampejo dependia do soberano desejo do narrador, daquele que quer contar, testemunhar para além de sua própria morte" (ibid., p.131). É este sentido profundo do narrar, esse lampejo em direção ao outro, que é indissociável da condição humana para os autores que estamos revisitando, aquilo que norteia as iniciativas mais interessantes de promoção da narração oral, no campo das artes, da memória cultural e da educação.

Uma ilustração desse impulso narrativo em direção ao outro, capaz de produzir poeticamente encontros e sentido comum, é a cena do romance Eva Luna, de Isabel 
Allende, em que uma contadora de histórias é procurada por um homem alquebrado pela guerra que pede que ela lhe venda um passado, pois o dele está cheio de sangue e gemidos e não serve para percorrer a vida" (ALLENDE, 1987, p.301). A mulher, então, passa a noite inteira narrando um bom passado para o guerreiro, inventando tudo, desde a vida de seus pais e a geografia de sua terra natal. A autora conclui:

\footnotetext{
Finalmente amanheceu e, às primeiras claridades do dia, ela comprovou que o cheio da tristeza se esfumara. Suspirou, fechou os olhos, e ao sentir o espírito vazio como o de um recém-nascido, compreendeu que, na ânsia de satisfazê-lo, tinha-lhe entregue sua própria memória, não sabia mais o que era dela e o quanto agora pertencia a ele, os dois passados haviam ficado enovelados em uma só trança. (ALLENDE, 1987, p. 301).
}

A abertura a novas possibilidades de relação entre memória e narrativa é sugerida, no âmbito do pensamento filosófico contemporâneo, também por JeanFrançois Lyotard. Embora o trabalho do autor, em um sentido mais amplo, chame atenção para o risco de perda cultural decorrente da crise da narrativa oral tradicional $^{4}$, sua valorização do potencial poético do momento da performance converge com o sentido do roteiro que estamos propondo aqui. Lyotard destaca o papel primordial da narração oral na formulação do conhecimento tradicional e observa que ela obedece a uma "pragmática da transmissão" em que o posto do narrador se baseia no fato de ele ter estado um dia no posto de ouvinte. Ele cita como exemplo uma fórmula caxinauá de começar a narração: "Esta é a história de...., como sempre a ouvi contar. Vou contá-la a ti, por minha vez. Escuta." ${ }^{5}$ ( LYOTARD, 1984, p. 20). A tradição narrativa envolve assim uma tripla competência: - saber fazer, saber dizer, saber ouvir - através da qual a comunidade se relaciona 
com ela mesma e com o ambiente, e é transmitido o conjunto de regras pragmáticas que constitui o laço social. Entretanto, observa o autor, a performance narrativa nas culturas tradicionais tem um significado em si, que muitas vezes independe do seu sentido referencial:

Por meio de uma ficção simplificadora, podemos lançar a hipótese de que, contra todas as expectativas, uma coletividade que toma a narrativa como sua forma-chave de competência não precisa lembrar de seu passado. Ela encontra o material bruto de seu laço social não apenas no significado das narrativas que reconta, mas também no ato de recitá-las. A referência das narrativas pode parecer pertencer ao passado, mas na verdade ela é sempre contemporânea do ato de recitação. É o ato presente que, em cada uma de suas ocorrências, introduz a temporalidade efêmera que habita 0 espaço entre o "eu ouvi" e o "você vai ouvir". (LYOTARD, 1984, p. 22).

Destacamos a passagem acima pela ênfase que ela dá à presença, ao valor único do que ocorre entre quem conta e quem ouve. Lyotard parece dizer que o laço social se fará desde que a comunidade se conte histórias, desde que ela fale de si mesma para si mesma, não importando tanto o que é que está sendo contado. A comunidade que fala de si ou para si está viva, pois o laço narrativo fertiliza o presente com o passado, e através da centelha que une quem conta a quem ouve faz com que eles partilhem por instantes de uma mesma "clareira imaginária" onde podem construir perspectivas comuns.

\section{ALINHAVOS FINAIS}

As ideias dos autores que trouxemos para compor este roteiro de leituras nos ajudam, acredito, a compreender o fenômeno de ressurgimento do interesse pela 
narração oral como instância de criação poética, verificado em grande parte do mundo a partir das últimas décadas do século XX. Diante da magnitude dos processos de urbanização, migrações, desenvolvimentos tecnológicos e intensificação da indústria cultural que caracterizam o capitalismo contemporâneo, a narração oral tradicional sem dúvida perdeu espaço, como percebia Benjamin. Como ele sugeria também, porém, novas narratividades poderiam surgir. E, pensamos, parecem estar surgindo.

O tom de Paul Ricoeur, na década de 1980, em sua aposta na permanência do papel central da narrativa na cultura, era menos o de uma análise intelectual do que o de fé e crença, por ele assumidamente não conseguir sequer imaginar uma humanidade que não contasse com a função narrativa para Ihe dar sentido. Hoje, olhamos ao redor e vemos manifestações dessa função, reconfigurada, e não só nas redes de narradores orais e na naturalidade com que hoje em contextos urbanos muitas pessoas identificam-se até profissionalmente como "contadores de histórias".

O esgotamento do paradigma difusional da comunicação, acompanhado da integração das tecnologias digitais e especialmente da internet ao cotidiano de milhões de pessoas abriu espaço para impulsos de resistência à massificação e à valorização da criação artística de indivíduos e grupos, por fora dos sistemas tradicionais de produção e distribuição comercial, no que vem sendo chamado de "cultura participativa" (JENKINS et. al, 2007). Pensar a arte verbal, hoje, exige levar em conta as possibilidades da arte em escala menor, portátil, independente, em que curiosamente parece haver muito em comum entre os contadores de histórias urbanos, os artistas orais cuja principal plataforma de performance é a internet e o poeta popular que encantava Paulo Freire em sua infância em Recife. No fazer narrativo e poético de todos eles vigora uma concepção disseminada de autoria - 
como a dos peixes milbocas do Mar de Histórias - , e uma forte marca da oralidade performática que, se nem sempre enuncia críticas à produção artística formulaica e comercial, quase sempre a ignora, ressignifica ou subverte. Seria essa vitalidade um exemplo das metamorfoses da função narrativa de que falava Ricoeur, ou das ressurgências sugeridas por Didi-Huberman? Talvez. Um fato é que os acervos disponíveis nas redes digitais (da cultura popular à indústria cultural, passando pelos clássicos da literatura e pelas produções alternativas ao consumismo) têm favorecido um intenso ziguezague entre o livro, a voz e a cena, assim como entre a memória, a tradição e a invenção. E a narração oral, inclusive pela independência e liberdade que autoriza aos criadores, é um dos fios possíveis para que as diversas formas artísticas aí presentes possam ser entretecidas de modos novos, a favor de pedagogias poéticas e em sintonia com as necessidades de sentido da contemporaneidade.

\section{NOTAS}

1 Possui doutorado em Ciências da Comunicação pela USP e pós-doutorado pela City University of New York. Professora do Centro de Educação, coordenadora do Núcleo Infância, Comunicação e Arte e da Oficina Permanente de Narração de Histórias da Universidade Federal de Santa Catarina (UFSC).

${ }^{2}$ Esta e as demais citações dessa obra foram traduzidas por mim.

\footnotetext{
${ }^{3}$ Aristóteles, no Capítulo IX da Poética: "o poeta deve ser mais um criador de narrativas (roteiros) do que de versos, na medida em que é poeta devido à imitação, e esta sua imitação é das ações."

(ARISTÓTELES, 2011,p. 56).

${ }^{4}$ Num certo sentido ele faz parte da tradição das narrativas sobre o fim da narrativa: é bem conhecido o seu conceito de crise das "grandes narrativas", designando formas de organizar a história características da modernidade, como o iluminismo, o romantismo, o marxismo.
} 
${ }^{5}$ Esta e as demais citações do autor foram traduzidas por mim.

\section{REFERÊNCIAS}

ALLENDE, Isabel. Eva Luna. Trad. Luiza Ibañez. Rio de Janeiro: Bertrand Brasil, 1987.

ARISTÓTELES. Poética. Trad. Edson Bini. São Paulo: EDIPRO, 2011.

BAUMAN, Richard. Verbal art as performance. American Anthropologist, v. 77, n. 2, p. 290-311, jun. 1975.

BAUMAN, Richard. A poética do Mercado Público: gritos de vendedores no México e em Cuba. Trad. Isabel S. de Rose. Ilha de Santa Catarina: UFSC, 2008. Coleção Antropologia em Primeira Mão.

BENJAMIN, Walter. Magia e técnica, arte e política. Trad. Sérgio Paulo Rouanet. São Paulo: Brasiliense, 1994. Obras Escolhidas, v. 1.

CALVINO, Italo. Seis propostas para o próximo milênio. São Paulo: Cia. das Letras, 1990.

DIDI-HUBERMAN, Georges. Sobrevivência dos vaga-lumes. Trad. Consuelo Salomé. Belo Horizonte: Editora UFMG, 2011.

FREIRE, Paulo. Conversam: Paulo Freire e Luiz Roberto Alves. In: ALVES, Luiz Roberto. Contos e casos populares. São Bernardo do Campo: Edições Liberdade, 1984.

GAGNEBIN, Jeanne Marie. Prefácio: Walter Benjamin, ou a obra aberta. In: BENJAMIN, Walter. Magia e técnica, arte e política. Trad. Sérgio Paulo Rouanet. São Paulo: Brasiliense, 1994a. Obras Escolhidas, v. 1.

GAGNEBIN, Jeanne Marie. História e narração em Walter Benjamin. Perspectiva: Fapesp; Unicamp, 1994b. 
JEAN, Georges. Los Senderos da la Imaginación Infantil: los cuentos, los poemas, la realidad. México, D.F.: Fondo de Cultura Económica, 1990.

JENKINS, Henry et al. Confronting the challenges of participatory culture: media education for the 21st century. Chicago: MacArthur Foundation, 2006. Disponível em: <http://digitallearning.macfound.org/att/cf/\%7B7E45C7E0-A3E0-4B89-AC9CE807E1B0AE4E\%7D/JENKINS_WHITE_PAPER.PDF>. Acesso em: 18 out. 2012.

KEARNEY, Richard. Narrativa. Trad. Gilka Girardello. Educação \& Realidade, PPGEdu/UFRGS, v. 37, n. 2, p.409-438, 2012.

LYOTARD, Jean-François. The postmodern condition: a report on knowledge. Minneapolis: University of Minnesota Press, 1984

RICOEUR, Paul. Tempo e narrativa. Trad. Marina Appenzeller. Campinas: Papirus, 1994. v. 1.

RICOEUR, Paul. Tempo e narrativa. Trad. Marina Appenzeller. Campinas: Papirus, 1995. v. 2.

RUSHDIE, Salman. Haroun e o mar de histórias. Trad. Isa Mara Lando. São Paulo: Paulicéia, 1991.

ZUMTHOR, Paul. Performance, recepção, leitura. Trad. Jerusa Pires Ferreira e Suely Fenerich. São Paulo: EDUC/PUC-SP, 2000. 